\title{
Hypomagnesaemia in chronic, stable asthmatics: prevalence, correlation with severity and hospitalization
}

\author{
O.S.B. Alamoudi
}

\begin{abstract}
Hypomagnesaemia in chronic, stable asthmatics: prevalence, correlation with severity and hospitalization. O.S.B. Alamoudi. (C)ERS Journals Ltd 2000.

ABSTRACT: Magnesium (Mg) deficiency is associated with airway hyperreactivity, wheeze and impairment of lung function. The prevalence of hypomagnesaemia, and its effect on asthma is unclear. Therefore, this prospective study was undertaken to evaluate the prevalence of low serum $\mathrm{Mg}$ level, to correlate whether hypomagnesaemia (serum Mg level $<0.74 \mathbf{m m o l} \cdot \mathrm{L}^{-1}$ ) is associated with severity of asthma and increased frequency of hospitalizations in chronic, stable asthmatics.

Ninety-three chronic stable asthmatics, who were on regular follow-up in an asthma clinic, were studied. On attendance to the asthma clinic, each subject was interviewed and clinically evaluated. The serum $\mathrm{Mg}$ level (normal $0.74-1.2 \mathrm{mmol} \cdot \mathrm{L}^{-1}$ ), as well as the severity of asthma was measured. The medications used were recorded. The total number of hospitalizations due to asthma exacerbation was scored for the last three months that preceded the date of measuring the serum $\mathrm{Mg}$ level.

Twenty-five patients $(27 \%)$ had a low Mg level with a mean $\pm S D$ of $0.69 \pm 0.04$ mmol $\cdot \mathrm{L}^{-1}$, while $68 / 93(73 \%)$ had a normal Mg level $\left(0.82 \pm 0.08 \mathrm{mmol} \cdot \mathrm{L}^{-1}\right)$. The number of hospitalizations in asthmatics with low Mg levels was 10/25 (40\%), compared to $8 / 68(12 \%)(\mathbf{p}<0.01)$ in asthmatics with normal Mg levels. Multiple logistic regression analysis showed that severe asthma was the only factor associated significantly with hypomagnesaemia $(p=0.04)$. No effect was observed for inhaled $\beta$ agonist, inhaled steroid or theophylline therapy on serum Mg level.

To conclude, hypomagnesaemia is common in chronic asthmatics. Chronic asthmatics with low Mg tend to have more hospitalizations than chronic asthmatics with normal Mg. Hypomagnesaemia was also associated with more severe asthma. Eur Respir J 2000; 16: 427-431.
\end{abstract}

Hypomagnesaemia has been suggested to be associated with increased incidence of wheeze, airway hyperreactivity, and impairment of lung function $[1,2]$. The mechanisms of action of magnesium $(\mathrm{Mg})$ on respiratory airways are multiple and include relaxation of airways smooth muscle, bronchodilatation, anticholinergic effect, and stabilization of the mast cells [3-5]. The prevalence of hypomagnesaemia in chronic asthmatics is unclear. One early report found a significant difference in serum $\mathrm{Mg}$ levels between asthmatics and the general population [6]. However, recent studies in acute and chronic asthma have shown no significant difference of serum Mg levels in asthmatics and nonasthmatic control subjects [7, 8]. In one study, it was found that measurement of serum $\mathrm{Mg}$ was not a reliable predictor for determining the severity of bronchial asthma (BA) [8]. Most of the previous studies on $\mathrm{Mg}$ [9-15] mainly concentrated on the use of $\mathrm{Mg}$ sulphate as a bronchodilator in acute asthma, with conflicting results. Recently, there has been growing evidence that low $\mathrm{Mg}$ intake may also play a role in the aetiology of asthma $[16,17]$. The occurrence of hypomagnesaemia in asthmatics was not fully explained, but it was partly attributed to the increased urinary excretion of $\mathrm{Mg}$, secondary to therapy used ( $\beta$-agonist, steroids, and xanthines) for management of asthma [18-21]. Although hypomagnesaemia has been reported in asthmatics, its prevalence in chronic asthmatics and its association with an increased number of hospitalizations or with severity of asthma is unknown.

The aims of this study were to detect the prevalence of hypomagnesaemia in chronic asthmatics and to assess whether chronic asthmatics with low $\mathrm{Mg}$ levels have a higher incidence of hospitalization. In addition, hypomagnesaemia is associated with severity of asthma and whether the therapeutic agents used in the management of chronic asthma have an effect on serum $\mathrm{Mg}$ level was also assessed.

\section{Materials and methods}

The study was approved by the human ethics committee of King Abdulaziz University Hospital (KAUH), and carried out in strict compliance of their policy. It was conducted from July 1997-June 1998 in the outpatient asthma clinic at KAUH. Laboratory tests were carried out in the Biochemistry Dept at KAUH.

Ninety-three consecutive chronic stable asthmatics on regular follow-up in the asthma clinic were studied. Patients were diagnosed according to the American Thoracic Society Criteria [22]. Diagnosis was based upon clinical 
history, reversibility of forced expiratory volume in one second (FEV1), or peak expiratory flow (PEF) $>15 \%$ and diurnal variations of peak expiratory flow rate $>20 \%$. The inclusion criteria were: signed consent form, age $\geq 14$ yrs, nonsmokers, and no history of renal disease, diabetes, hypertension, cardiac disease, diarrhoea, alcohol abuse, diuretic use or current pregnancy. Hospitalizations were taken into account only if their sole reason was an asthma exacerbation.

Chronic asthmatics, who accepted to take part in the study were interviewed, clinically evaluated, and their PEF measured. A questionnaire that included the patient's age, sex, duration of BA, nocturnal symptoms, and number of hospitalizations (if any) was obtained from each subject and checked against their hospital notes.

Score for drug therapy according to RoLLA et al. [19] with modifications was assigned to each patient according to inhaled $\beta$-agonist use $(1=<$ once per day, $2=$ every day, $3=>$ recommended dose; inhaled corticosteroids $1=$ use, $2=$ no use irrespective of duration of therapy; theophylline $1=$ use, $2=$ no use; and oral steroid $1=$ use, $2=$ no use).

The severity of chronic asthma while on therapy was graded into mild, moderate, and severe according to the international consensus report on diagnosis and management of asthma [23]. Severity of asthma was measured according to the patient's symptoms and PEF measurements. Mild asthma was diagnosed if intermittent symptoms were < once per week; nocturnal symptoms were < twice per month, asymptomatic between exacerbations, PEF $>80 \%$ pred; and PEF variability $<20 \%$. Moderate asthma was diagnosed if nocturnal asthma symptoms were $>$ twice per month, exacerbations $>1-2$ times per week, PEF $60-80 \%$ pred, and PEF variability was $>30 \%$. Severe asthma was diagnosed if continuous symptoms, frequent nocturnal asthma and frequent or life-threatening exacerbations, $\mathrm{PEF}<60 \%$ of pred, PEF variability $>30 \%$.

The total number of hospitalizations in asthmatics was scored for the last three months that preceded the date of measuring the serum $\mathrm{Mg}$ level. In asthmatics with hospitalization $(n=18)$, the date of discharge from the hospital was recorded for each one. The measurement of serum $\mathrm{Mg}$ level was only done on the sixth week onwards after discharge from hospital to avoid any effect of therapy (nebulized $\beta$-agonists and i.v. steroids) on their serum $\mathrm{Mg}$ levels. Hospitalizations were scored when the sole reason for admission was an acute exacerbation of asthma. All asthmatics with hospitalization were hospitalized once during the last three months.

In the asthma clinic, serum $\mathrm{Mg}$, potassium $(\mathrm{K})$, calcium $(\mathrm{Ca})$, phosphorus $(\mathrm{P})$, albumin, urea, and creatinine levels were measured for each subject. Serum $\mathrm{Mg}$ levels were measured using an atomic absorption spectrophotometer (Hitachi 917; Hitachi, Tokyo, Japan). The normal serum $\mathrm{Mg}$ value measured in the laboratory was $0.74-1.2 \mathrm{mmol}$. $\mathrm{L}^{-\mathrm{P}}$. Hypomagnesaemia was considered to be present if serum Mg level $<0.74 \mathrm{mmol} \cdot \mathrm{L}^{-1}$. Measurements of PEF were carried out using Wright's peak flow meter (Ferraris Medical Ltd, Edmonton, London, UK).

\section{Data management and statistical analysis}

Data were entered in a data base file and scrutinized for outliers. The statistical analysis was done using SPSS statistical package (SPSS-PC, 444N. Michigan Avenue, Chicago, Ill., USA). Frequency distributions were compared using the chi-square test or Fisher's exact test. The unpaired t-test and analysis of variance (ANOVA) were used to compare mean values. Multiple logistic regression analysis was performed to adjust for the confounding variables and to identify important risk factors associated with hypomagnesaemia. Confidence intervals and tests of significance were computed based on maximum likelihood estimation of the logistic parameters. For all tests a p-value of $<0.05$ was considered significant.

\section{Results}

A total of 93 chronic stable asthmatics were studied. They were divided into 68 chronic asthmatics with normal serum $\mathrm{Mg}$ with a mean \pm SD of $0.82 \pm 0.08 \mathrm{mmol} \cdot \mathrm{L}^{-1}$ and 25 chronic asthmatics with low serum $\mathrm{Mg}$ with a mean \pm SD of $0.69 \pm 0.04 \mathrm{mmol} \cdot \mathrm{L}^{-1}$ (table 1$)$.

The prevalence of hypomagnesaemia was found to be $27 \%$. The number of hospitalizations in chronic asthmatics with low $\mathrm{Mg}(40 \%)$ was significantly higher than found in chronic asthmatics with normal Mg $(11.8 \%),(p=0.04)$. Mean duration of asthma in chronic asthmatics with low $\mathrm{Mg}$ was (8.4 $\pm 7.3 \mathrm{yrs})$ slightly shorter than in chronic asthmatics with normal $\mathrm{Mg}(10.3 \pm 10.6 \mathrm{yrs})$ however, this was not significant. In an univariate analysis, a higher proportion of severe asthma (28\%) was found in chronic asthmatics with low Mg compared with normal Mg levels $(12 \%)$, although this was not significant (table 1). In patients with hypomagnesaemia, there were more hospitalizations in patients categorized as severe asthmatics, compared to moderate and mild asthmatics $(85 \%, 23 \%$, $20 \%$ respectively, $\mathrm{p}<0.05$ ).

Among $\beta$-agonist users, the proportion who used it $<$ once per day, every day, or more than recommended, did not differ significantly between patients with normal $\mathrm{Mg}$ compared to patients with low $\mathrm{Mg}$. In addition, the proportion that used inhaled steroids and theophylline therapy in both groups did not differ significantly. Multiple logistic regression analysis was performed to adjust for

Table 1. - Characteristic features of bronchial asthmatics (BA) with normal and low magnesium (Mg) levels

\begin{tabular}{|c|c|c|c|}
\hline & $\begin{array}{l}\text { BA with } \\
\text { normal Mg }\end{array}$ & $\begin{array}{l}\text { BA with } \\
\text { low } \mathrm{Mg}\end{array}$ & p-value \\
\hline Patients $n$ & 68 & 25 & \\
\hline $\begin{array}{l}\text { Serum Mg level } \\
\mathrm{mmol} \cdot \mathrm{L}^{-1}\end{array}$ & $0.82 \pm 0.08$ & $0.69 \pm 0.04$ & \\
\hline $\begin{array}{l}\text { Serum albumin level } \\
\mathrm{mmol} \cdot \mathrm{L}^{-1}\end{array}$ & $44.8 \pm 4.2$ & $45.0 \pm 3.7$ & NS \\
\hline $\mathrm{M} / \mathrm{F}$ & $13 / 55$ & $2 / 23$ & NS \\
\hline Age yrs & $40.8 \pm 13.9$ & $36.8 \pm 10.3$ & NS \\
\hline Duration of asthma yrs & $10.3 \pm 10.6$ & $8.4 \pm 7.3$ & NS \\
\hline $\begin{array}{l}\text { Number of } \\
\text { hospitalizations }\end{array}$ & $8 / 68(11.8 \%)$ & $10 / 25(40 \%)$ & 0.01 \\
\hline \multicolumn{4}{|l|}{ Severity of asthma } \\
\hline Mild & $39(57 \%)$ & $13(52)$ & \\
\hline Moderate & $21(31 \%)$ & $15(20 \%)$ & \\
\hline Severe & $8(12 \%)$ & $7(28 \%)$ & NS \\
\hline PEF & $317.5 \pm 98.4$ & $306.4 \pm 112.2$ & NS \\
\hline
\end{tabular}

NS: not significant; PEF: peak expiratory flow; M: male; F: female. 
Table 2. - Multiple logistic regression coefficients and calculated adjusted odds ratio (OR) estimates with $95 \%$ confidence interval $(\mathrm{Cl})$ for risk factors associated with hypomagnesaemia among asthmatics

\begin{tabular}{|c|c|c|c|c|c|}
\hline Variables & Coefficient & SEM & p-value & OR & $95 \% \mathrm{CI}$ \\
\hline Age yrs & -0.0308 & 0.0230 & 0.181 & 0.97 & $0.925-1.015$ \\
\hline Sex & -0.9903 & 0.8998 & 0.271 & 2.69 & $0.926-4.454$ \\
\hline Duration BA & -0.0289 & 0.0348 & 0.406 & 0.97 & $0.902-1.038$ \\
\hline Severity BA & 0.9087 & 0.4432 & 0.040 & 2.48 & $1.611-3.349$ \\
\hline$\beta$-agonist use & -0.2615 & 0.6292 & 0.678 & 0.77 & $-0.463-2.003$ \\
\hline Steroid use & 0.0058 & 0.7377 & 0.994 & 1.01 & $-0.436-2.456$ \\
\hline $\mathrm{K}$ & -1.7992 & 0.9393 & 0.055 & 0.17 & $-1.671-2.011$ \\
\hline $\mathrm{P}$ & -1.9492 & 1.2121 & 0.108 & 0.14 & $-2.236-2.516$ \\
\hline $\mathrm{Ca}$ & 2.0992 & 2.4226 & 0.386 & 8.16 & $3.412-12.908$ \\
\hline
\end{tabular}

BA: Bronchial asthma; K: potassium; P: phosphorus; Ca: calcium.

confounding variables and to identify important risk factors associated with hypomagnesaemia among chronic asthmatics (table 2). Severity of asthma was the only variable with a statistically significant odd ratio (OR) of 2.48 (95\% CI 165-3.35). This means that among chronic asthmatics severe asthma is more likely to be associated with hypomagnesaemia than mild and moderate asthma. Other variables did not contribute significantly to the model.

\section{Discussion}

In this study, which was performed on 93 chronic stable asthmatics, three important results were found. Firstly, the prevalence of hypomagnesaemia was up to $27 \%$; secondly, chronic asthmatics with low $\mathrm{Mg}$ had a higher incidence of hospitalization; and finally, chronic asthma with low $\mathrm{Mg}$ was associated with more severe asthma.

The effects of hypomagnesaemia on asthmatics are not yet well defined. Most of the previous studies concentrated mainly on the use of $\mathrm{Mg}$ sulphate as a bronchodilator in $\beta$ agonist resistant asthma [9-15]. A few studies on animals showed that $\mathrm{Mg}$ has a protective effect on respiratory airways through different mechanisms of actions that lead to relaxation of airway smooth muscle and bronchodilatation of asthmatic airways [3-5]. Some reports showed an association between $\mathrm{Mg}$ deficiency and an increased airway hyperreactivity and pulmonary vascular resistance $[1,2]$.

Hypomagnesaemia is probably the most common under-diagnosed electrolyte disturbance in medical practice. Its prevalence in hospitalized patients is variable and may range from $4.6-47 \%$ depending on the type of population studied $[24,25]$. The highest prevalence of hypomagnesaemia was reported for patients in intensive care units, reaching up to $65 \%$. Its prevalence in most respiratory disorders including asthma was unknown. In a previous study by Rolla et al. [19] on 95 patients with chronic obstructive airway disease, the prevalence of hypomagnesaemia was found to be $11 \%$. In acute asthma, studies have shown conflicting reports on the prevalence of hypomagnesaemia $[6,8]$. The prevalence of hypomagnesaemia found in the present study was unexpectedly high. However, a higher prevalence was observed in an earlier report by HAURY et al. [6] who found $50 \%$ of the 26 patients with acute asthma had hypomagnesaemia. In contrast to this, FALKNER et al. [8] found that serum $\mathrm{Mg}$ level in 23 patients with acute asthma was similar to the 15-control nonasthmatic subjects [8]. In both studies, however, the total number of asthmatics studied was too small to draw a clear conclusion about prevalence of hypomagnesaemia among asthmatics. In addition, the purposes of these two studies were mainly to evaluate the effect of $\mathrm{Mg}$ sulphate as bronchodilator, rather than to evaluate the prevalence of hypomagnesaemia among asthmatics. Recently, DE VALK et al. [26] also found no difference in the serum, and red cell $\mathrm{Mg}$ levels between 20 mild asthmatics and 20 normal control subjects. However, this may have been due to the fact that all the asthmatics had mild asthma and the total number was also small.

There has been no previous study to evaluate whether low serum $\mathrm{Mg}$ can trigger acute asthma or is associated with increased frequency of hospitalizations, in chronic, stable asthmatics. In this study a statistically significant higher incidence of acute asthma and hospitalization reaching up to $40 \%$ was found in chronic asthmatics with low $\mathrm{Mg}$ compared to $11.8 \%$ in chronic asthmatics with normal $\mathrm{Mg}, \mathrm{p}<0.01$. However, it is not clear why chronic asthmatics with low $\mathrm{Mg}$ have a higher incidence of hospitalizations. One possible explanation is that low serum $\mathrm{Mg}$ may increase airway hyperreactivity, and hyperresponsiveness that renders chronic asthmatics with low $\mathrm{Mg}$ more prone to developing bronchoconstriction and acute exacerbations of asthma. This may occur through either increased production of acetylcholine at cholinergic nerve endings [4] or through increased histamine release from mast cells [5], or may be through increased $\mathrm{Ca}$ flux into airways smooth muscle cells $[27,28]$. In addition, there may be other possible unknown mechanisms by which hypomagnesaemia may cause bronchoconstriction and consequently increase the incidence of hospitalization among chronic asthmatics.

In the present study, measurements of serum Mg levels were performed in asthmatics with mild to severe asthma, where levels were found to be low, and which correlated significantly with severity of asthma, $\mathrm{p}<0.04$. By reviewing the literature, there has been no previous study that investigates the correlation between low serum $\mathrm{Mg}$ level and severity of asthma. EMELYANOv et al. [29] found a correlation between airway hyperreactivity and lower red cells $\mathrm{Mg}$ levels in asthmatics when compared with normal subjects. This was attributed to the low $\mathrm{Mg}$ intake in asthmatics. The correlation between low red cell $\mathrm{Mg}$ level and severity of asthma was not attempted in their study, 
which could be an additional factor along with nutritional causes to explain the low red cell $\mathrm{Mg}$ level in asthmatics.

In previous studies, the occurrence of hypomagnesaemia in the management of acute asthma has been attributed to the use of $\beta$-agonists either orally [30] or intravenously [18] or by nebulization [21]. In the present study all the subjects studied were chronic, stable asthmatics and none were on oral, intravenous or nebulized $\beta$-agonist. They were also not on oral steroid therapy, or recently discharged from hospital, during measurements of serum $\mathrm{Mg}$ level, so its unlikely that low serum $\mathrm{Mg}$ levels were due to the effect of therapy received in hospital. Multiple logistic regression analysis showed that there was no association of hypomagnesaemia with inhaled $\beta$-agonists, inhaled steroids, theophylline therapy, $\mathrm{K}, \mathrm{Ca}$, or $\mathrm{P}$ in chronic asthmatics. Therefore, it is not known which factor is responsible for the hypomagnesaemia in chronic asthmatics.

Recently, an association between dietary $\mathrm{Mg}$ intake and the occurrence of asthma was shown. BRITTON et al. [16] found that low dietary $\mathrm{Mg}$ intake was associated with increased incidence of airway hyperreactivity, wheeze, and impairment of lung function in normal subjects. HILL et al. [7] found that high $\mathrm{Mg}$ intake $\left(400 \mathrm{mg} \cdot \mathrm{day}^{-1}\right)$ in 20 asthmatics was associated with significant improvement of asthma symptom scores, though there was no significant improvement in FEV1, provocative dose of methacholine causing a $20 \%$ fall in FEV1 (PD20), PEF variables, or decrease of bronchodilators used. However, the duration of $\mathrm{Mg}$ administration may be too short to detect any improvements in their pulmonary functions. Therefore, in this present study, the possibility of low Mg intake causing hypomagnesaemia cannot be ruled out and the dietary pattern in asthmatics may need to be investigated. It is possible that severe asthmatics may have more nutritional deficiencies than mild asthmatics and consequently may have lower Mg levels. However, further studies are needed to clarify these speculations.

In this study, the serum $\mathrm{Mg}$ level was only used to evaluate the presence of hypomagnesaemia in chronic asthmatics because of its availability in KAUH institution. Although, it may not reflect accurately the total body $\mathrm{Mg}$ store, it was found to be significantly reduced in asthmatics. Additional measurement of $\mathrm{Mg}$ level, either in the red cells, leukocytes or in the urine would have probably strengthened the findings if levels were also found to be low in asthmatics. These tests, however, are difficult to perform and are available only in specialized centres. The absence of a healthy control group was another drawback in this study. But the difference between normal and low $\mathrm{Mg}$ is still potentially relevant even with a different cut-off between normal and hypomagnesaemia in chronic asthmatics.

In summary, this study performed in chronic stable asthmatics, showed a high prevalence of hypomagnesaemia. Hypomagnesaemia was associated with significantly higher incidence of hospitalizations and correlated with severe asthma. The cause of hypomagnesaemia in chronic asthmatics remains unclear. Whether $\mathrm{Mg}$ supplementation in asthmatics with hypomagnesaemia has a role in controlling asthma should be studied.

Acknowledgements. The author would like to thank T. Ghabrah for both consultations in the analysis and editing of the manuscript.

\section{References}

1. Dhingra S, Solven F, Wilson A, McCarthy D. Hypomagnesemia and respiratory muscle power. Am Rev Respir Dis 1984; 129: 497-498.

2. Rolla G, Bucca C. Hypomagnesemia and bronchial hyperreactivity. A case report. Allergy 1989; 44: 519-521.

3. Spivy WH, Skobelof EM, Levin RM. Effect of Mg chloride on rabbit bronchial smooth muscle. Ann Emerg Med 1990; 19: 1107-1112.

4. Del Castillo J, Engbeak L. The nature of the neuromuscular block produced by Mg. $J$ Physiol 1954; 124: 370 384.

5. Bois P. Effect of Mg deficiency on mast cells and urinary histamine in rats. Br J Exp Path 1963; 44: 151-155.

6. Haury VG. Blood serum Mg in bronchial asthma and its treatment by administration of $\mathrm{Mg}$ sulfate. J Lab Clin Med 1940; 26: 340-344.

7. Bernstein WK, Khastgir T, Khastgir A, et al. Lack of effectiveness of $\mathrm{Mg}$ in chronic stable asthma. Arch Intern Med 1995; 155: 271-276.

8. Falkner D, Glauser J, Allen M. Serum Mg levels in asthmatic patients during acute exacerbation of asthma. Am J Emerg Med 1992; 10: 1-3.

9. Okayama H, Aikawa T, Okayama M, Sasaki H, Mue S, Takishima T. Bronchodilating effect of intravenous $\mathrm{Mg}$ sulfate in bronchial asthma. JAMA 1987; 257: 10761078.

10. Skobeloff EM, Spivey WH, McNamara RM, Greenspoon $\mathrm{L}$. Intravenous $\mathrm{Mg}$ sulfate for the treatment of acute asthma in the emergency department. JAMA 1989; 262: 1210-1213.

11. Bloch H, Silverman R, Mancherje N, Grant S, Jagminas $\mathrm{L}$, Scharf SM. Intravenous $\mathrm{Mg}$ sulfate as an adjunct in the treatment of acute asthma. Chest 1995; 107: 15761581.

12. Sydow M, Crozier TA, Zielmann S, Radke J, Burchardi $\mathrm{H}$. High-dose intravenous $\mathrm{Mg}$ sulfate in the management of life-threatening status asthmaticus. Intensive Care Med 1993; 19: 467-471.

13. Noppen M, Vanmaele L, Impens N, Schandevyl W. Bronchodilating effect of intravenous $\mathrm{Mg}$ sulfate in acute severe bronchial asthma. Chest 1990; 97: 373-376.

14. Green SM, Rothrock SG. Intravenous Mg for acute asthma: failure to decrease emergency treatment duration or need for hospitalization. Ann Emerg Med 1992; 21: 260-265.

15. Chande VT, Skoner DP. A trial of nebulized Mg sulfate to reverse bronchospasm in asthmatic patients. Ann Emerg Med 1992; 21: 1111-1115.

16. Britton J, Pavord I, Richards K, et al. Dietary Mg, lung function, wheezing, and airway hyperreactivity in a random adult population sample. Lancet 1994; 344: 357362.

17. Hill J, Micklewright A, Lewis S, Britton J. Investigation of the effect of short-term change in dietary $\mathrm{Mg}$ intake in asthma. Eur Respir J 1997; 10: 2225-2229.

18. Bos WJW, Postma DS, Doormaal JV. Magnesiuric and calciuric effects of terbutaline in man. Clinical Science 1988; 74: 595-597.

19. Rolla G, Bucca C, Burgiani M, Oliva A, Branciforte L. Hypomagnesemia in chronic obstructive lung disease: effect of therapy. Mg Trace Elem 1990; 9: 132-136.

20. Knutsen R, Bohmer T, Falch J. Intravenous theophyllineinduced excretion of calcium, $\mathrm{Mg}$ and sodium in patients with recurrent asthmatic attacks. Scan J Clin Lab Invest 1994; 54: 119-125. 
21. Bodenhamer J, Bergstrom R, Brown D, Gabow P, Marx JA, Lowenstien SR. Frequently nebulized $\beta$-agonists for asthma: effects on serum electrolytes. Ann of Emerg Med 1992; 21: 1337-1342.

22. American Thoracic Society. Standards for the diagnosis and care of patients with chronic obstructive pulmonary disease (COPD) and asthma. Am Rev Respir Dis 1987; 139: 225-244.

23. International Consensus Report on Diagnosis and Management of Asthma 1992. Publication No 92-3091. National Heart, Lung and Blood Institute. Bethesda, Maryland 20892. National Institute of Health.

24. Al-Ghamdi SMG, Cameron EC, Sutton RAL. Mg deficiency: in depth review-pathophysiologic and clinical overview. Am J Kid Dis 1994; 24: 737-752.

25. Whang R. Mg deficiency: pathogenesis, prevalence, and clinical implications. AmJMed 1987; 82: Suppl.3A, 24-29.
26. De Valk HW, Kok PT, Struyvenberg A, et al. Extracellular and intracellular $\mathrm{Mg}$ concentrations in asthmatic patients. Eur Respir J 1994; 6: 1122-1125.

27. Emelyanov A, Fedoseev G, Barnes PJ. Reduced intracellular $\mathrm{Mg}$ concentration in asthmatic patients. Eur Respir J 1999; 13: 38-40.

28. Gustafson T, Boman K, Rosenhall L, Sandstrom T, Wester PO. Skeletal muscle $\mathrm{Mg}$ and $\mathrm{K}$ in asthmatics treated with oral beta 2-agonists. Eur Respir J 1996; 9: 237-240.

29. Kass RS, Lederer WJ, Tsien WJ, Wiengart R. Role of calcium ions in transient inward currents and after contractions induced by strophanthidin in cardiac Purkinge fibers. J Physiol 1978; 281: 187-208.

30. Dunnet J, Naylan WG. Calcium efflux from cardiac sacroplasmic reticulum: effects of calcium and Mg. $J \mathrm{Mol}$ Cell Cardiol 1987; 10: 487-498. 